\title{
A NARRATIVA VISUAL EM LIVROS ÁGRAFOS
}

José Salmo Dansa de Alencar

Pontifícia Universidade Católica do Rio de Janeiro - PUC Rio

salmo.dansa@gmail.com

Prof. Dr. Luiz Antonio Luzio Coelho

Pontifícia Universidade Católica do Rio de Janeiro - PUC Rio

artcoel@puc-rio.com.br

Resumo: A proposta deste artigo é apresentar o percurso de formação e as principais características da narrativa em livros ágrafos, através de suas raízes ontológicas e históricas que ligam as duas principais tipologias desta espécie de livro: os livros de imagem, da Literatura infantil e os livros de artista, das Artes visuais. As estruturas narrativas, apresentadas como dimensão temporal do objeto-livro, são decorrentes de aproximações e analogias a elementos da Literatura e gêneros bibliográficos. Nesse sentido, apontamos que essas qualidades são resultantes do ambiente favorável, das condições materiais, do potencial estético conseguido pelas técnicas de ilustração e o surgimento da 'subjetividade da criança' entre os séculos dezenove e vinte. Por fim, apresentamos e exemplificamos essas formas narrativas como manifestações em livros de artista.

Palavras-chave: Literatura, artes visuais, narrativa visual, livro ágrafo, ilustração.

\begin{abstract}
The purpose of this article is to present the way of forming and the main narrative characteristics of textless books, through its ontological and historical roots that link the two main types of this kind of book: the textless books, from children's literature and artist books, from visual arts. The narrative structures, presented as temporal dimension of the book object, are due to approximations and analogies to elements of literature and bibliographic genres. In this sense, we point out that these qualities are the result of the prosperous environment, the material conditions, the aesthetic potential achieved by the illustration techniques and the emergence of the 'subjectivity of the child' between the nineteenth and twentieth century. Finally, we present and exemplify these narrative forms as manifestations in five artist books.
\end{abstract}

Keywords: Literature, visual arts, visual narrative, textless book, illustration. 


\section{INTRODUÇÃO}

O presente artigo consiste na apresentação de formas de narrativas por imagens em livros ágrafos, apresentando exemplos das tipologias de maior incidência: os livros de imagem pertencente à Literatura infantil e os livros de artista, pertencente às Artes visuais. As obras apresentadas foram coletadas em dois acervos de livros: a coleção de livros de imagem da International Youth Library (IJB), de Munique, através de uma bolsa de pesquisador residente, em 2008, e, o segundo, o acervo de livros de artista do Research Centre for Artists' Publications - Weserburg, de Bremen, em 2014. O material resultante desses contatos tornou-se objeto de estudo da pesquisa de doutorado intitulada Estudo das dimensões do livro ágrafo, iniciada em 2014, no Departamento de Arte e Design da Puc-Rio.

As bases teóricas foram utilizadas na descrição do percurso de formação dessa espécie de livro (FEBRVRE \& MARTIN, 1992; HAINING, 1981); para buscar indícios da presença de analogias, seja com a narrativa verbal em gêneros literários (FAVERO, 1983), seja pela influência de outros meios, gêneros bibliográficos e tipologias de livros (FLUSSER, 2005; AUMONT, 2009; SILVEIRA, 2008; EISNER, 2010). O trabalho parte de uma apresentação do objeto, descrição do problema e metodologia, e, em seguida, dois blocos de desenvolvimento. O primeiro consiste na apresentação de uma breve historiografia dos livros ágrafos, exemplificada pela imagem de três exemplares históricos do acervo da IJB e o segundo descreve formas e analogias da narrativa visual através de livros de artista do acervo do Weserburg.

\section{DESENVOLVIMENTO}

O problema deste estudo está relacionado às características formais e conceituais das estruturas narrativas para estabelecer possíveis critérios de análise da imagem e da narrativa visual que correspondem às questões que abrangem as tipologias de livros ágrafos. Essa investigação é proveniente de percepções de pesquisas anteriores e faz uso de uma metodologia de análise específica, fundamentada na estética da visualidade do livro que vê a narrativa visual como uma das quatro dimensões do espaço/tempo que constituem o livro.

A análise dos livros por uma metodologia específica da imagem tem em conta que, a produção de livros ágrafos faz parte da práxis dos ilustradores, artistas visuais e designers, enquanto os estudos da narrativa nos livros de imagem tem sido um domínio quase que exclusivo de especialistas da Literatura infantil e Pedagogia, campos onde as imagens são estudadas em sua relação com as palavras. A percepção a respeito dos processos de produção da narrativa por imagens na contemporaneidade, a influência da narrativa verbal e de outros meios nos levaram a buscar pontos de vista acerca da estética do livro ágrafo que coincidam com questões da práxis do Design e das Artes visuais, partindo da seguinte questão: Quais as especificidades narrativas dos livros ágrafos?

Consideramos o livro ágrafo como um objeto pluridimensional, onde se pode distinguir quatro dimensões do espaço/tempo, inter-relacionadas de forma sistêmica e definidas como: linha, plano, objeto e narrativa. Nossa metodologia de análise é descritiva, fenomenológica e seu fundamento principal é a definição de Vilém Flusser, onde as imagens seriam o "resultado do esforço de se abstrair duas das quatro 
dimensões de espaço-tempo, para que se conservem apenas as dimensões do plano." (FLUSSER, 2005, p.7)

Esse percurso leva em consideração a primeira dimensão, que tem na linha o cerne de seu vocabulário e representações baseadas no desenho; a segunda dimensão, o plano, que diz respeito às imagens que ocupam as páginas e seu foco principal é a ilustração; e a terceira dimensão, que tem no objeto livro, elementos de sua materialidade e encadernação como focos principais; e privilegia a quarta dimensão, tema deste artigo, que diz respeito ao tempo e, consequentemente, à narrativa por imagens. Nosso objetivo é descrever, identificar e exemplificar tipos de narrativas e as possíveis interseções com gêneros literários e entre tipos de livros ágrafos.

\subsection{A formação do livro ágrafo}

Começo e fim são pontos opostos no espaço e no tempo, estrutura que contém toda a realidade. Dentre as possibilidades de representação da passagem do tempo pela configuração de uma forma narrativa, o livro talvez seja a forma de maior extensão histórica e influência sobre outros meios. A formação do livro ágrafo no ocidente acontece inicialmente pelo desenvolvimento da gravura e das publicações populares de cunho religioso, destinadas às classes menos abastadas na Idade Média. Posteriormente, no, século XIX, a indústria de livros destinados à infância vai impulsionar a produção de uma gama variada de tipos de livros de imagem.

A raiz mais remota dos livros ágrafos são os chamados block books, com indícios datando do século XV, anteriores aos livros impressos com tipos móveis de Johannes Gutenberg, em 1455. Esses livros eram predominantemente ágrafos, destinados à evangelização do leitor iletrado ou semiletrado e suas publicações mais conhecidas foram a Biblia Pauperum e o Speculum.

Lucien Febvre explica que, naquele momento, a técnica de impressão alemã era dominante na Europa e que ela desenvolveu-se graças ao círculo da ourivesaria, que viabilizou o domínio da fundição para produção de tipos móveis, mas, sobretudo, pela qualidade das tintas com consistência apropriada e a partir da chegada do papel de fabricação italiana, que desde a metade do século XIV já era utilizado e, "no final desse século, tinha se tornado mercadoria corrente." (FEBVRE \& MARTIN,1992. p.68)

O período necessário para a maturação do livro ágrafo como obra de arte pode ser entendido pela correspondência com o período de disseminação das técnicas da gravura nos séculos XVII e XVIII e por sua aplicação como instrumento auxiliar da alfabetização. Nesse percurso, há uma convergência de relações ontológicas e históricas entre autores e obras, como, por exemplo, artistas que ilustraram livros infantis, mas também livros ilustrados aos quais, tempos depois, se imputou certa aura artística, como parte do que Canclini nomeia como "processos de hibridação presente em manifestações culturais." (CANCLINI, 2011. p.XXVII)

A seguir, apresentamos três exemplos de livros ágrafos, que representam pontos cruciais desde os primórdios da espécie, passando pela chamada Era de ouro, até o surgimento da narrativa visual. Estes exemplos são resultado de uma pesquisa de campo onde pudemos registrar uma amostragem significativa de exemplares históricos e as principais manifestações desses livros, até o século XX. O trabalho consistiu em uma listagem do acervo da International Youth Library (IJB) de Munique, 
registros fotográficos, análise morfológica dos objetos, e resenhas abrangendo tema, aspectos da configuração e comentários constantes na bibliografia histórica.

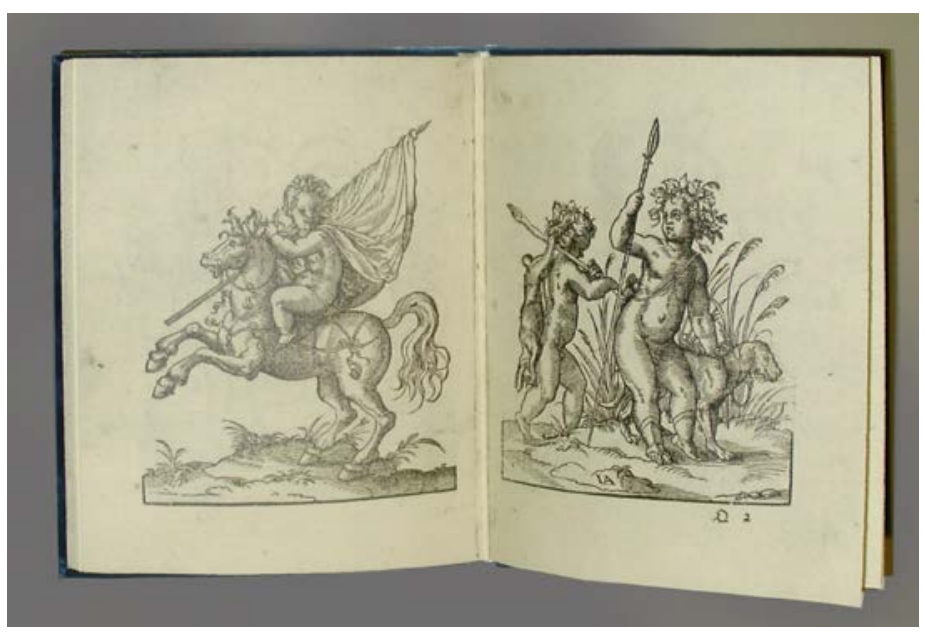

Figua 1: “Kunst-und-Lehrebüchlein” Fonte: Internationale Jugendbibliotek München

O livro para pintar Kunst-und-Lehrebüchlein (Fac-símile - Sttutgart: Verlag Mueller und Schidler, 1971/Düsseldorf: Arnz, 1578) é reconhecido por seu pioneirismo histórico, sendo o primeiro livro de imagem que se tem notícia. A obra tem formato médio e vertical; impresso em xilografia P\&B sobre papel vergé; capa dura, lisa, revestida com tecido e encadernação costurada. O miolo traz frontispício ilustrado, capitular e texto introdutório com tipologia gótica, identificando título e destinação. A partir daí, o conteúdo é composto por 78 folhas que trazem uma série de xilogravuras descrevendo o imaginário social da época em pequenas cenas para pintar.

As historiadoras Joyce Walley e Tessa Chester atribuem a autoria ao ilustrador: "Ainda no século XV o pintor e ilustrador Jost Amman produziu um dos primeiros livros ilustrados para jovens, ainda que voltado para instrução, Livro de Arte e Educação para jovens pelo qual eles podem aprender e pintar, foi publicado em 1580 e não tem texto." (WALLEY \& CHESTER, 1988) Essa noção, no entanto, contradiz versão anterior, na qual o historiador Peter Haining ignora o ilustrador e defende que o livro é uma coletânea de imagens reunida pelo editor, da seguinte forma: "Esse livro de arte e instrução para jovens é uma coletânea de ilustrações em xilogravura sobre a vida contemporânea, fábulas e contos folclóricos complementados com legendas, os quais foram reunidos de várias fontes por Sigmund Feyerabend." (HAINING, 1979)

O desenvolvimento da linguagem visual em livros ágrafos, seja na forma mais poética dos livros de artista, seja de forma mais narrativa nos livros de imagem, teve no século XIX uma inegável contribuição dos livros infantis. Essas obras tinham grande qualidade material e estética e grande variedade de tipos, como livros para pintar, livros pop-up, peep-shows e livros ágrafos descritivos, com ilustrações retratando objetos e cenas, destinados à alfabetização. Esse aumento e aprimoramento qualitativo resultaram do desenvolvimento da cromolitografia, industrialização dos processos gráficos, surgimento de uma literatura dedicada à infância, qualidade artística dos ilustradores e o início da valorização da subjetividade da criança. 


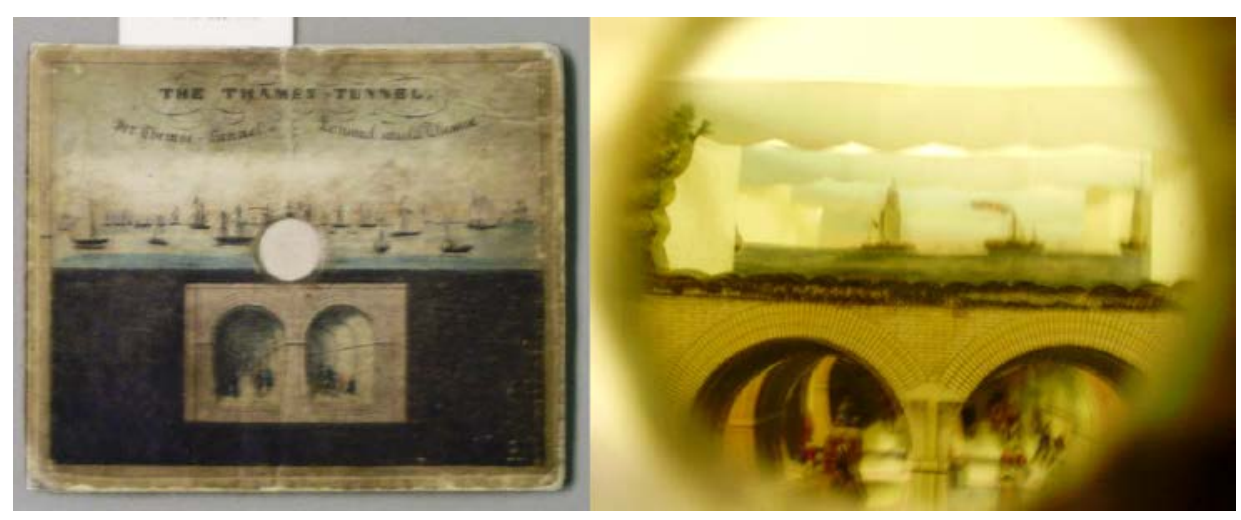

Figua 2: “The Tames Tunnel” Fonte: Internationale Jugendbibliotek München

O pequeno livro The Tames Tunel (Londres: S\&J Fuller, 1850) é um belo exemplo do experimentalismo e excelência técnica de um momento histórico chamado Era de ouro dos livros ilustrados. A obra tem formato horizontal, capa dura com encadernação colada, ilustração e faca circular no centro. O miolo, assim como a capa, tem impressão em cromolitografia e é composto por cinco folhas impressas em cores, com faca especial e descreve um túnel sob o rio Tâmisa. O observador/leitor vê, pelo circulo central, na parte de cima, a imagem do rio, da arquitetura local e barcos em distâncias diversas. Na parte de baixo, vê-se a imagem do túnel, pessoas, veículos e animais.

Peter Haining, no seu livro Movable Books, afirma que o editor S\&J Fuller foi um dos primeiros a pensar e realizar essa ideia que é, na verdade, uma miniaturização e adaptação de um 'aparato cinemático' da época. O autor nos mostra outro exemplo similar do mesmo editor e afirma que, "o peep-show foi uma modalidade que ganhou rápida popularidade nos primeiros tempos dos Toy-books. Eles evoluíram a partir dos antigos peep-shows itinerantes que os apresentadores costumavam fazer pelo interior (da Europa)." (HAINING, 1979. p.22)

Além desses experimentos e do grau de refinamento da ilustração no final do século XIX, os historiados concordam que o ambiente enfatizava o estímulo visual e havia um gosto por livros extravagantemente e opulentos, onde se notava, no requinte das produções, a perfeita harmonia entre ilustração, encadernação e tipografia. Os editores rapidamente tiraram vantagem dessas condições favoráveis dadas pelo momento econômico e social. 


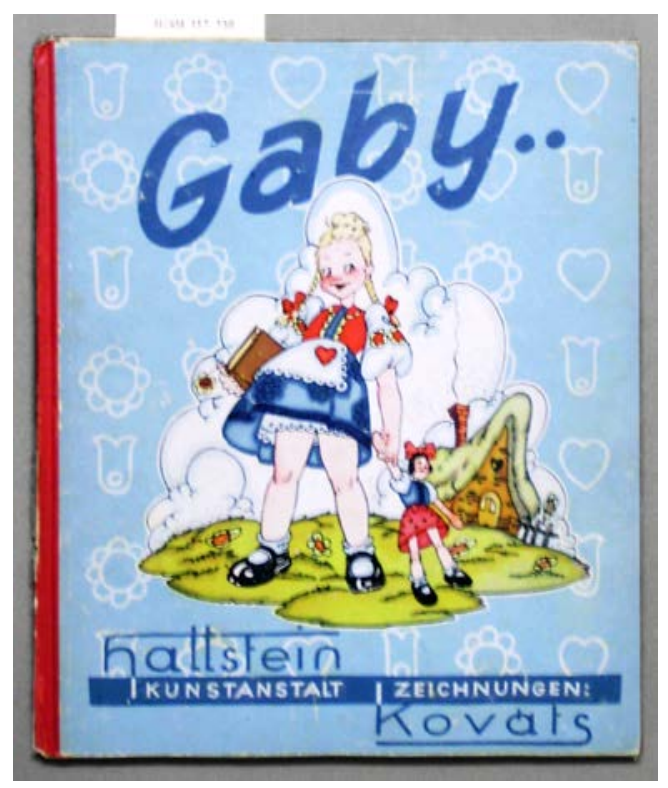

Figua 3: "Gabi.." Fonte: Internationale Jugendbibliotek München

O livro Gabi.. foi o vigésimo de uma lista cronológica de 613 livros de imagem do acervo da IJB e o primeiro a trazer uma narrativa visual clara, que se desenrola em uma linha cronológica, com começo, meio e fim. A obra tem formato vertical, lombada, capa dura e encadernação costurada; e sua configuração traz título, autor, editora, ilustração centralizada e grafismo vazado em fundo azul médio. O miolo é composto por doze páginas, cada uma com uma ilustração em cores, centralizada e com área branca ao redor. A narrativa consiste em uma série de cenas que descreve um dia da personagem, desde o momento que acorda até a hora de dormir.

Há uma simplicidade encantadora na história, proveniente de um tempo que já não existe mais, e, no entanto, o livro representa uma grande inovação, um avanço muito significativo na arte de contar histórias através de imagens. Com a presença da narrativa visual, tornou-se cada vez mais comum o uso do livro de imagem como ferramenta de estímulo à criação textual em sala de aula, e, com o uso da semiologia como instrumento de análise surgiu a noção de que os livros de imagem se organizam sobre um texto subjacente.

Outra noção que empurrou as fronteiras da área de Letras para abordagens sobre as imagens foi reconsiderar o que poderia ser chamado de texto. Por exemplo, em uma definição não muito recente, Favero considera que a manifestação de uma textualidade não se restringe a textos verbais, "mas também pictóricos, arquitetônicos, fílmicos ou quaisquer outros podem ser concebidos como textos, isto é, como manifestações de uma textualidade." (FAVERO, 1983. p.20-21)

Entendemos a narrativa visual como representação de um tipo de estrutura proposta como projeto, e, nesse sentido, identificamos inicialmente dois grandes grupos, que podemos chamar de estrutura narrativa espacial e estrutura narrativa causal. O primeiro tipo tem o encadeamento de sua sequência circunscrito ao espaço interno do livro. Em geral, em uma estrutura circular. Por exemplo, no livro lda e volta, de Juarez Machado (Belo Horizonte: Agir, 1976), a condução da história resulta da sequência de pegadas atravessando as páginas e é justamente a estrutura circular que permite a personagem caminhar ao longo das páginas e capas, evidenciando o interesse do autor pelo uso de todo o livro como suporte. 
O segundo tipo segue uma forma linear, sob uma ordem cronológica e uma tendência para a organização dos fatos na forma de roteiro. O deslocamento espacial de personagens é característico das narrativas sucessivas, onde são comuns as analogias ao cinema e recursos gráficos das historias em quadrinhos. O livro Sapo a passo, de Laurent Cardon (São Paulo: Biruta, 2012), segue essa tendência que funciona como uma espécie de storyboard. A influência dessa estrutura narrativa semelhante às HQs propicia que muitos livros tenham suas histórias configuradas a partir de uma forma narrativa de descrever uma ação que Scott McCloud chama "cena a cena". (McClOUD, 2007)

\subsection{A narrativa por imagens}

O percurso de formação do livro de imagem foi fundamental para a criação de um repertório visual em livros de artista, seus aspectos materiais, técnicos e na formulação de um imaginário que concerne especificamente ao universo bibliográfico. Tendo em conta que a narrativa visual se dá primordialmente por imagens e suas possibilidades de significação, concordamos com Jacques Aumont quando considera a narrativa como, "(...) conjunto organizado de significantes, cujos significados constituem uma história." (AUMONT, 2009. p.255)

O livro de artista, como o entendemos hoje e suas variações de conteúdo exclusivamente imagético, surgem somente em meados do século passado. No entanto, essa noção de Leonor Favero, que defende que o leitor poderia imaginar, atribuir sentido e a criar textos verbais ou narrativas durante a fruição está alinhada ao pensamento de Paulo Silveira, quando, nas conclusões de sua tese sobre As existências de narrativas nos livros de artista, afirma que:

(...) o autor desta pesquisa confessa sua incapacidade em olhar a fonte de R. Mutt e aceitá-la seca e silenciosa, mas sim projetar o acontecimento, fazer desenrolar o evento, vê-la com os olhos da fantasia, enfim funcionando em profusão, devolvendo com vigor todo o líquido dourado que teria recebido se não se tornasse um objeto de arte. (SILVEIRA, 2008. p.306)

Silveira reconhece as existências de narrativas "tradicionais e lineares ou não" em livros de artista. Na maior parte dos casos, condicionada à própria estrutura do códice e a sequência de páginas, e, ainda, segundo este autor, à narrativa está diretamente relacionada à oposição entre os livros de artista impressos em série e as obras únicas categorizadas como livros-objeto, ou seja, (...) "quase se poderia estabelecer uma equação na qual arte serial é igual à arte narrativa (essa é uma verdade para a maioria dos trabalhos)." (Idem. p.305)

A seguir, apresentamos quatro exemplos de livros ágrafos contemporâneos do acervo do Research Centre for Artists' Publications - Weserburg, de Bremen, representando variações significativas da narrativa visual, suas influências e analogias a partir de gêneros literários (que relacionamos ao conteúdo) como a biografia, o mini conto, o romance histórico e, também, gêneros bibliográficos (que relacionamos à forma) como as histórias em quadrinhos e os livros infantis. 


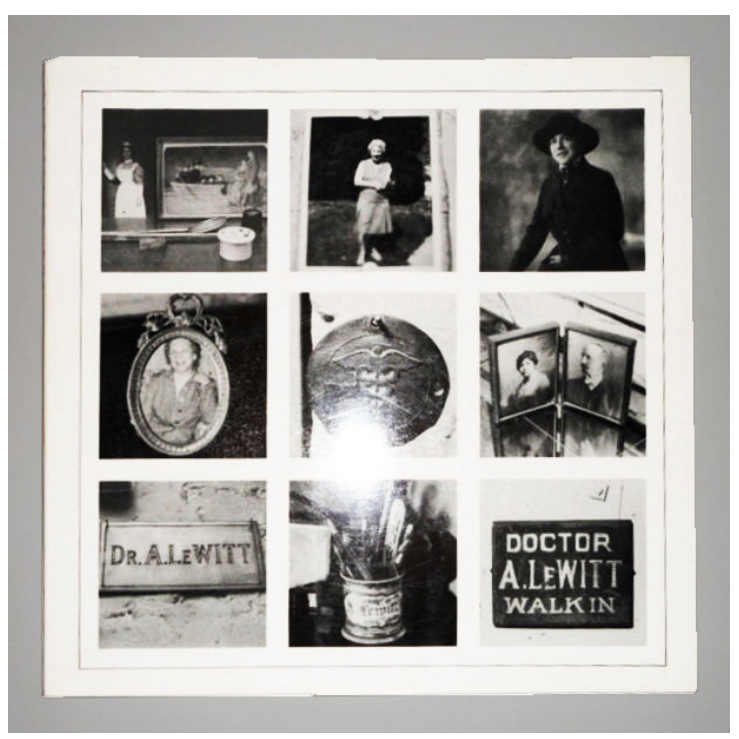

Figura 4: “Autobiography” Fonte: Studienzentrum für Küntlerpublikationen Bremen

O livro Autobiography de Sol Lewitt (New York: Multiples \& Torf, 1980) tem formato grande, quadrado, encadernação do tipo brochura, capas impressas em papel cartão branco e envolto em uma sobrecapa de alta gramatura, ilustrada em P\&B. Miolo composto de 126 páginas e mais de mil fotografias de objetos do entorno do estúdio do artista, incluindo encanamento, luminárias, tomadas de parede, frascos de geleia, esses objetos trazem, muitas vezes, as marcas de desgaste, como sinais da passagem do tempo e parece contemplar dois lados de Sol LeWitt: o artista e o colecionador. O título, evocando o gênero literário biografia, reafirma a característica narrativa e essencialmente bibliográfica da obra.

O modo de dividir a página como módulos de nove quadrados proporcionais ao formato total da página, a consequente simetria entre as páginas, o preto e branco das fotos reafirmado nas molduras que subdividem as páginas, mostram o rigor do artista em contraste com a variedade e o ecletismo das fotos do colecionador. Há um discurso das imagens conduzido pela organização da obra, que sugere tanto a estrutura quanto a linearidade, tanto o todo da página quanto a sequência. Essa organização das imagens induz à leitura, em analogia à tradição da linguagem escrita, a partir da esquerda para a direita e de cima para baixo.

Sol LeWitt constituiu uma extensa coleção de obras de seus contemporâneos, além de objetos e imagens coletadas em outras áreas, incluindo xilogravuras japonesas, fotografias turísticas coloridas à mão, fotografia modernista e partituras de compositores como Steve Reich e Philip Glass. Curiosamente, em sentido oposto ao rigor conceitual de sua obra, todo seu acervo era formado com uma abordagem não hierárquica, seguindo um padrão eclético e o valor afetivo, talvez essa seja a maior marca minimalista em seu esforço em negar a representação do mundo e a narrativa.

Seja por analogia à tradição de contar histórias, seja pelos traços deixados por essa tradição nos meios que assumiram essa função, a narrativa continua perpetuando-se em diversas maneiras, inclusive na forma gráfica. Por exemplo, a gestação e o desenvolvimento na contemporaneidade da narrativa na forma hipermídia ou daquilo que viria a se tornar o cinema no início do século passado fez surgir grande diversidade de formas narrativas e certamente continuará a gerar decorrências e a influenciar outras formas da contar histórias. 
No caso do cinema, houve uma intensa troca entre os meios gráficos e suas imagens, seja na busca de representação do movimento pela arte futurista, seja através dos cartazes, no processo criativo através de storyboards, ou ainda, a reconhecida influência sobre as tiras de humor publicadas nos jornais que viriam a se tornar historias em quadrinhos, como conhecemos hoje. Das manifestações estéticas influenciadas pelo cinema podemos apontar dois tipos distintos de imagem narrativa em livros que assumiram estruturas bem definidas: os flip books, que poderíamos de antemão qualificar uma como imagem pré-cinema e as histórias em quadrinhos, que podemos considerar como imagem pós-cinema.

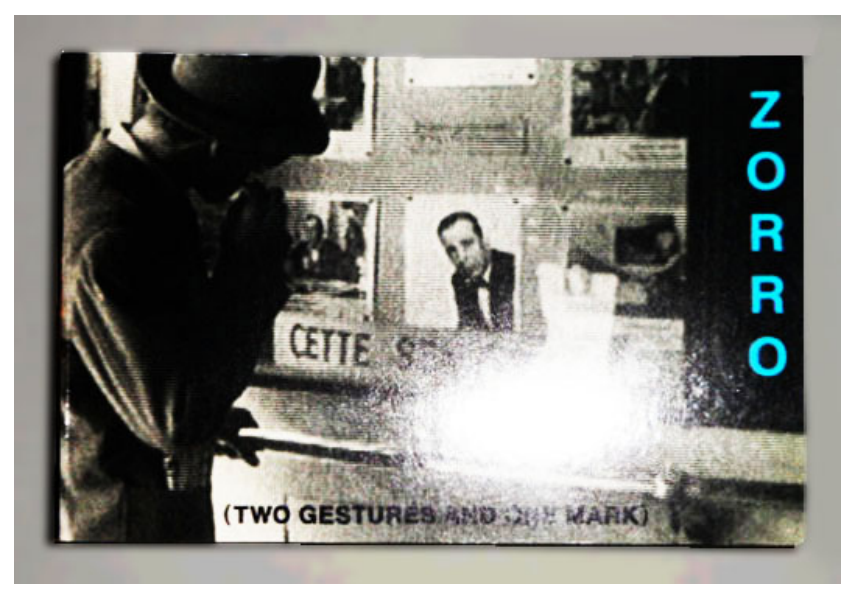

Figura 5: "Zorro" Fonte: Studienzentrum für Küntlerpublikationen Bremen

O pequeno flip book, de formato horizontal, Zorro, de John Balderassi (Köln: Oktagon, 1998) tem encadernação colada, capa impressa em duas cores e verniz sobre papel de gramatura média. $O$ miolo traz três séries de fotos $P \& B$ : a primeira série traz o personagem sugerindo um apresentador; na segunda, vemos o personagem Zorro marcando o " $Z$ " com a ponta da espada numa parede e; na terceira sequência temos o ator Humphrey Bogart sorrindo. Todas as imagens são sangradas nas páginas.

O flip book é um pequeno livro que traz uma sequência de imagens organizadas de modo que, ao tomá-lo em uma das mãos, podemos passar suas páginas com o polegar da outra mão, produzindo ilusão de movimento. Com uma média ideal de trinta páginas, mas podendo chegar até uma centena, para que o movimento tenha boa visualização, eles representaram uma forte ligação entre o objeto livro, a série de desenhos e a imagem animada. No entanto, a obra de Balderassi vai além dessas especificidades da tipologia e vai assimilar uma característica literária, conjugando três narrativas em uma obra, fazendo, assim, surgir um ponto de convergência estética entre o flip book e o mini conto. Estas duas tipologias marginais, associadas pelo livro, têm em comum a natureza breve da narrativa, o aspecto minimalista e a especificidade formal que, de certo modo, explicam-lhes a fragilidade como gênero e inconstância de suas produções.

Existindo desde o século XIX, são muito raros os flip books dedicados às crianças, ainda que sejam, muitas das vezes, considerados como um tipo de brinquedo, sendo, assim como os quadrinhos e os livros de imagem, um gênero desvalorizado a priori. A historiografia dos livros raramente aborda esses livros, ficando a cargo dos estudos do livro de artista as poucas e breves vinculações deles ao 
livro objeto ou ao livro de artista, como na publicação de Johanna Drucker, The Century of Artist Books. (DRUCKER, 2004)

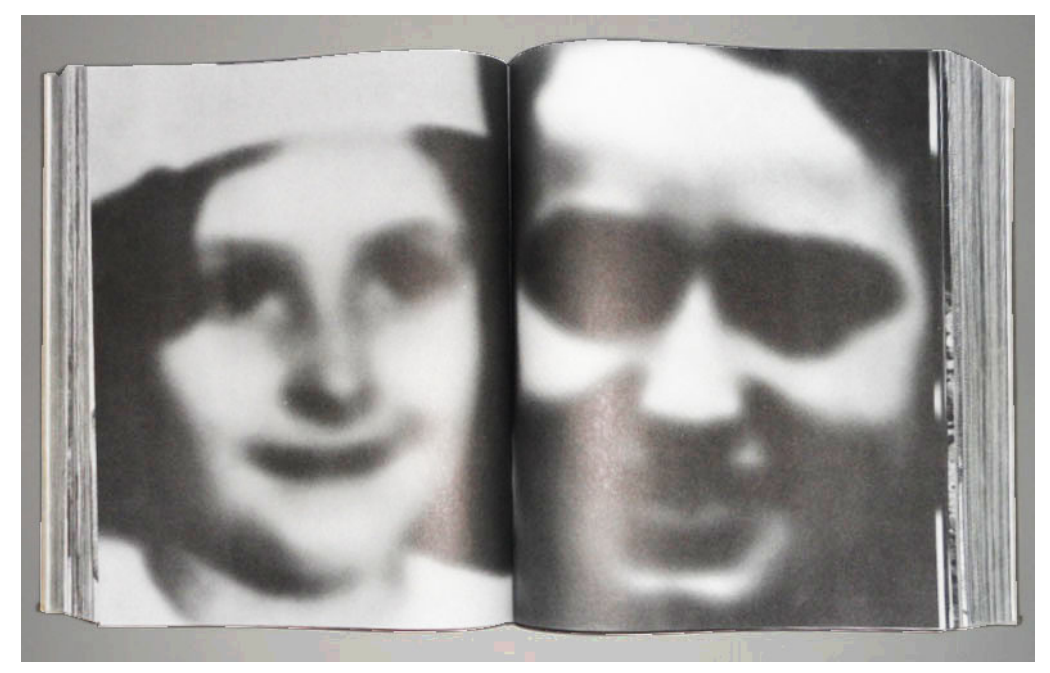

Figura 6: "Kaddish" Fonte: Studienzentrum für Küntlerpublikationen Bremen

O livro Kaddish, de Christian Boltansky (München, London, New York: Gina Kehayoff Verlag, 1998), tem formato grande, encadernação costurada, capa dura e sobrecapa em duas cores, sobre papel couché fosco. O miolo traz, em 1168 páginas, 1.138 imagens fotográficas advindas de fotógrafos amadores, catálogos de escolas, fotos esquecidas dentro de livros e álbuns de famílias. O livro é impresso em offset sobre papel bíblia, um tipo de papel de baixa gramatura e, ao mesmo tempo, resistente, usado em obras extensas como enciclopédias e bíblias, tornando-se, assim, um elemento associado ao título da obra, nome de um canto fúnebre, uma oração judaica recitada na sinagoga, no final de seções mais importantes de adoração a Deus.

Este tipo de obra, chamada livro catálogo, tem estrutura predominantemente descritiva, mas com seu potencial narrativo ligado à sequencialidade. No caso desta magnífica obra, as imagens ganham reverberação através da translucidez das páginas que, junto à escala e posição das figuras e objetos nas sequências de cada seção, parecem criar uma analogia à memória pela possibilidade de quase antever a próxima imagem na transparência das folhas.

Kaddish possui quatro subtítulos que determinam a divisão do conteúdo em quatro séries de imagens ao longo de sua extensa narrativa visual. $O$ primeiro chamase Menschlich (Humanidade) que é o título de uma exposição realizada em 1994, no Kunstmuseum Liechtenstein. À primeira vista, Menschlich se parece com o livro de Boltansky intitulado Monument, produzido a partir da exposição homônima, cuja instalação trazia fotografias de vítimas do Holocausto. Os outros subtítulos aparecem na seguinte ordenação: Örtlich (localidade), Sterblich (mortalidade), Sachlich (materialidade).

Percebe-se a concomitância entre o referido evento histórico e a composição artística desde o conceito que rege a obra, elementos materiais e na forma de conjugar esses fundamentos. Essa maestria está na longa extensão do livro; sua subdivisão em blocos, como se fossem capítulos; e na analogia à memória, perceptível na própria articulação dos materiais. As memórias do nazismo na França perpassam toda a extensa obra de Boltansky e ressurgem de forma impactante e silenciosa neste 
livro. Essa conjunção de história e ficção nos faz associá-lo ao romance histórico.

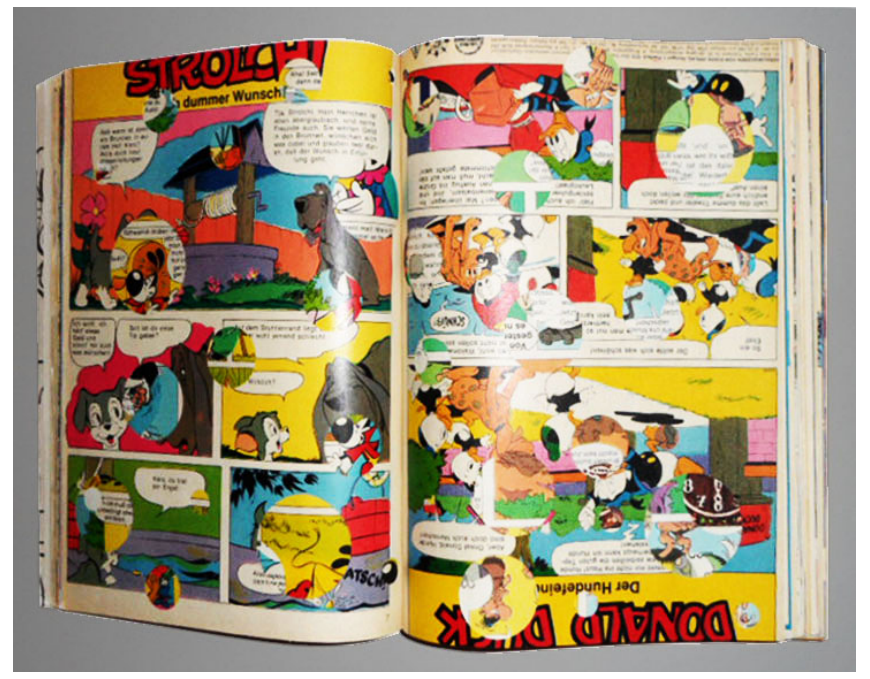

Figura 7: “Gesammelte werk - band 7" Fonte: Studienzentrum für Küntlerpublikationen Bremen

Em sentido conceitual diametralmente oposto a Kaddish, abordando a dinâmica narrativa dos livros para crianças e jovens, temos Gesammelte Werke, de Dieter Roth (Stuttgart/London: Edition Hansjörg Mayer, 1974). O livro tem formato médio, encadernação colada, tipo brochura e capa flexível P\&B. O miolo traz 250 páginas e a obra é dividida em duas partes: $3 \mathrm{~b}$ e $3 \mathrm{~d}$. A primeira foi produzida com partes de HQs coloridas e a segunda com partes de livro de imagens preto e branco, do tipo livro para pintar e ligue os pontos, ambas as partes contendo recortes circulares, em tamanhos diferentes, deixando partes das páginas anteriores e posteriores à mostra.

Esta obra faz parte de uma série de livros que Roth fez agrupando e unificando formatos de folhas de acerto, utilizadas por gráficas comerciais para preparar e alinhar as cores antes da impressão e corte definitivo, de HQs e livros de imagem. Estes livros resultantes foram publicados em pequenas edições, mas cada volume é único, já que cada conteúdo foi ditado pela disponibilidade do material da gráfica naquele momento.

O trabalho traz grande luminosidade e o tom lúdico do material usado, potencializado pelo contraste entre a forma dos cortes circulares, a forma angular dos quadrinhos e as partes das páginas seguintes que são deixadas a ver. O livro preserva 0 aspecto experimental, presente em muitos dos livros de Dieter Roth, e, neste caso, a narrativa parece ser subvertida pela força do objeto e das imagens. No entanto, o que se percebe é uma reformulação de narrativas mais longas para trechos fragmentados onde a visualidade das histórias predomina sobre sua verbalidade.

A ambiguidade dessas obras nos serve como questionamento sobre os rótulos sociais e a submissão aos modelos de representação na cultura. A subversão do sentido em uma história em quadrinhos, um extenso agrupamento de fotos sobre papel bíblia, um flip book com três sequências ou uma coleção de objetos pessoais podem ser vistos como anomalias narrativas ou nos fazer repensar códigos e significados nas narrativas como forma de representações da passagem do tempo. 


\section{CONCLUSÃO}

A quarta dimensão do espaço/tempo ou dimensão temporal repercute o último tópico da Fenomenologia do objeto, de Abraham Moles, que trata do ciclo de vida dos objetos, como uma analogia a passagem do tempo, desde as narrativas ancestrais até as narrativas visuais. Nas palavras de Moles, "o indivíduo, portanto, está ligado finalmente a cada etapa". (MOLES, 1981. p.98)

Os livros de artista analisados acima trouxeram a tona questões como o colecionismo e suas características documentais na obra Autobiography, de LeWitt; em seguida, o flip book Zorro, de Baldessari, evidencia suas particularidades narrativas que relacionamos ao mini conto, por sua especificidade e a natureza breve; o livro Kaddish, de Boltansky, de forte caráter documental que relacionamos ao gênero literário do romance histórico; as estruturas narrativas das HQs e livros infantis encontram-se subvertidas em uma obra lapidar de Roth, cujas incisões circulares deixam a mostra trechos anteriores e posteriores do livro.

A narrativa bibliográfica que surge no século XX resultou da efervescência da produção do século anterior em contato com a chegada do cinema e estruturas como o flip book e as HQs, que se mantiveram como parte deste vocabulário até hoje. A plenitude da arte bibliográfica na chamada Era de ouro dos livros ilustrados surge em decorrência de condições materiais, técnicas e da valorização da subjetividade da criança.

No entanto, há uma relação ontológica na formação do livro ágrafo, presente desde as primeiras incidências nos block books e posteriormente em livros infantis, que traziam uma relação estrita com a arte, tornando-se, ao longo do tempo, o canal da expressão artística em livros. Este percurso teve suas raízes ligadas à educação, pela difusão de textos sagrados ao publico iletrado e semiletrado, que vai perpetuar o viés pedagógico dos livros de imagem na alfabetização.

Deste modo, compreendemos que todos os aspectos narrativos do livro ágrafo resultam de um percurso secular, que conjuga sua instrumentalização na educação, as tecnologias da indústria gráfica e as qualidades estéticas da ilustração. Nesse sentido, o livro ágrafo tem vocabulário próprio cunhado nesses aspectos estéticos, técnicos e instrumentais, mas também analógicos a outros gêneros literários e bibliográficos.

\section{REFERÊNCIAS}

AUMONT, Jacques. A imagem. São Paulo: Papirus, 2012.

EISNER, W. Quadrinhos e arte sequencial. São Paulo: Martins Fontes, 2010.

FÁVERO, Leonor L. \& KOCH, Ingedore G.V. Linguística Textual: uma introdução. São Paulo: Cortez, 1983.

FEBVRE, L. \& MARTIN, H. J. O aparecimento do livro. São Paulo: Unesp, 1992.

FLUSSER, Vilém. Filosofia da caixa preta. São Paulo: Relume Dumará, 2005.

HAINING, P. Movable books. Illustrated history. London: New English Library, 1979.

McCLOUD, Scott. Desenhando Quadrinhos. São Paulo, M. Books, 2007

MOLES, Abraham. Teoria dos objetos. Rio de Janeiro: Tempo Brasileiro, 1981 
SILVEIRA, P. As existências da narrativa no livro de artista. 2008. 321 f. Tese (doutorado) - Universidade Federal do Rio Grande do Sul, Curso de Pós-Graduação em Artes visuais.

WHALLEY, J. Irene \& CESTER, T. Rose. A History of Children's Book Illustration. London. John Murray (publishers) Ltd and Victoria and Albert Museum. 1988. 